\title{
EDITORIAL
}

\section{From the desk of the Editor-in-Chief: Welcome to the first issue of Trends in Immunotherapy}

It gives me great pleasure and honor to announce the launching of Trends in Immunotherapy (TI). TI is an open-access, peer-reviewed journal encompassing various disciplines related to the immune-based therapeutic method. The journal covers all areas of immunotherapy including:

- Cancer immunotherapy

- Immunomodulators

- Antibodies

- Allergy disorder and immunotherapy

- Therapeutic method for auto-immune disorder

- Immunotherapy cell-products

- Cytokines application

- Immuno-modulatory effects of natural products

Preliminary studies, pre-clinical and clinical investigative reports are welcomed. The journal accepts original research article, review article, case reports and short communications.

As you know, cancer is a disease that threatens life, and many scientists have challenged it for the cure and care. From 1970s, immunology has made an explosive progress and several immunological treatments were tried. However, the results were not good. In the $21^{\text {st }}$ century, the situation has changed dramatically under a much better understanding of molecular immuno-editing system, resulting in more advanced and more effective treatments including immune checkpoint inhibitors and comprehensive immunotherapy. Of course, recent advances in immunotherapy have given bright hopes in many fields such as inflammatory diseases, allergic diseases, as well as in drug discoveries.

It has been a hard but exciting way to recognize how preparations were made in moving forward the journal's editorial matters: visiting EnPress Publisher office for discussions, developing friendship for better editorship, inviting and selecting editors and peer reviewers, reviewing the articles, suggesting and advising the authors about changes in the drafts, and making the final decisions. Also, frankly speaking, I had to get used to computer-based editor system.

I acknowledged the authors who submitted scientific articles that have been chosen for publication in the first issue. I have to thank the Publisher, the Managing Editor, the Editorial Board Members and reviewers for their kind support and time to judge the manuscripts. I also wish to express my gratitude, on behalf of everyone involved with TI.

Our future mission is to contribute to the perfect cure and care of patients through immunotherapy and to deepen the field of immunology. TI promises to offer all scientists and patients quality medicine from laboratory bench to bedside and vice versa.

Fukumi Furukawa Editor-in-Chief

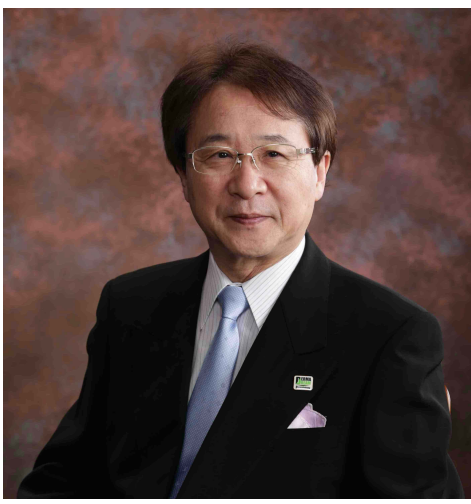

\section{About the Editor-in-Chief:}

Emeritus Prof. Fukumi Furukawa, MD, PhD, graduated from Kyoto University, Japan, in 1982. He has been the Vice Director of Wakayama University Hospital (2010-2014) and Professor and Chairman of the Department of Dermatology, Wakayama Medical University (1999-2017). Recently, he serves as the President of Takatsuki Red Cross Hospital, Japan. He is actively involved in society and academic activities: President of Japanese Society for Dermatoallergology (2003-2007), Chief Organizer of $2^{\text {nd }}$ International Conference on Cutaneous Lupus Erythematosus 2008, President of Japanese Society for Aesthetic Dermatology (2009-2011), President of Japanese Society for Dermatoallergology and Contact Dermatitis (2011-2013) and President of the 114 Annual Meeting of Japanese Dermatology Association (2015). He was awarded a Dermatology Foundation Fellowship Award (1985) and Congressus Mundi Dermatologie Scientific Poster Award (1987). 